\title{
Effect of grammatical gender on visual word recognition: Evidence from lexical decision and eye movement experiments
}

\author{
PASCALE COLÉ \\ University of Savoie and C.N.R.S., Chambéry, France \\ JOËL PYNTE \\ C.N.R.S. and University of Provence, Provence, France \\ and \\ PASCALE ANDRIAMAMONJY \\ University of Nice-Sophia Antipolis, Nice, France
}

\begin{abstract}
Lexical decision times and eye movements were recorded to determine whether grammatical gender can influence the visual recognition of isolated French nouns. This issue was investigated by assessing the use of two types of regularities between a noun's form and its gender-namely ending-to-gender regularities (e.g., the final letter sequence-at appears only in masculine nouns and, thus, is predictive of masculine gender) and gender-to-ending regularities (e.g., feminine gender would predict the final letter $e$, whereas masculine gender would not). Previous studies have shown that noun endings are used by readers when they have to identify gender. However, the influence of ending-to-gender predictiveness has never been investigatedin a lexical decision task, and the effect of gender-to-ending regularities has never been evaluated at all. The results suggest that gender information can influence both the activation stage (Experiments 1 and 3) and the selection stage (Experiments 2 and 3) of the word recognition process.
\end{abstract}

Grammatical gender is a phenomenon found in many languages, but not much is known about its communicative function. It is not a major subject of research in psycholinguistics, and few data are available on the role of gender in language comprehension. There are two reasons for this. First, rather than being studied in its own right, grammatical gender has generally been used as a tool for addressing other issues, such as anaphor resolution (Arnold, Eisenband, Brown-Schmidt, \& Trueswell, 2000; Bates, Marangolo, Pizzamiglio, \& Dick, 2001; Cacciari, Carreiras, \& Cionini, 1997; Carreiras, Garnham, \& Oakhill, 1993; Garnham, Oakhill, Ehrlich, \& Carreiras, 1995; McDonald \& MacWhinney, 1995; Vigliocco \& Zilli, 1999), deficits in aphasia (Akhutina et al., 2001; Blumstein, Milberg, Dworetzky, Rosen, \& Gershberg, 1991; Jakubowicz \& Goldblum, 1995; Jarema \& Friederici, 1994), and the autonomy of the subprocesses involved in visual word recognition (Colé \& Segui, 1994; Gurjanov, Lukatela, Lukatela, Savic, \& Turvey, 1985). Second, studies using gender have

Correspondence concerning this article should be addressed to P. Colé, University of Savoie, Laboratoire de Psychologie Expérimentale (C.N.R.S./U.M.R. 5105), Campus de Jacob Bellecombette, B.P. 1104, 73011 Chambéry Cedex, France (e-mail: pascale.cole@univ-savoie.fr). been interested mainly in its syntactic component(Deutsch, Bentin, \& Katz, 1999; Friederici \& Jacobsen, 1999), which redundantly marks noun gender on items governed by gender agreement rules (adjectives, articles, personal pronouns, etc.). According to Corbett (1991), the agreement system is the essence of grammatical gender. Gender agreement is thought to facilitate the resolution of pronoun anaphors (Corbett, 1991) and help reinforce syntagmatic cohesion within utterances by pointing to the noun modified by an adjective (Desrochers, 1986; Lyons, 1968; Mel'cuk, 1993). As such, the part played by grammatical gender in language comprehension is generally reduced to its role in the agreement system. But gender also has a lexical component.

\section{The French Gender System}

The lexical component assigns every noun to a gender category. The number of genders is not limited to two: "Four is common and twenty is possible"(Corbett, 1991). In many languages around the world, there are obvious semantic principles behind the distinction of genders, at least for part of the lexicon (principles based on physical sex, animacy, and so forth). In Indo-European languages, whose gender systems are based on a division of masculine/feminine or masculine/feminine/neuter, there is a frequent connec- 
tion of grammatical gender and physical sex, but the degree of correspondence between the semantic and the grammatical categories is usually quite weak. In French, for example, each noun is either masculine or feminine. Few can be masculine and feminine, and a category change generally implies a meaning change (e.g., le mémoire [memoir]-la mémoire [memory]). Gender categorization is partly semantic, since nouns referring to males are generally masculine and nouns referring to females generally feminine (e.g., le père [the father]-la mère [the mother]). However, semantically motivated gender categories correspond only for $10.5 \%$ of French nouns (Séguin, 1969). For the remaining $89.5 \%$, the assignment of a gender category is not based on any general rule (e.g., le bureau [the desk]-la table [the table]). In French, as in many other languages, gender is a property that appears to show no sign of any systematicity, and generative linguists have often adopted the view that gender is simply a lexical property, which has to be learned.

On the other hand, descriptions of the French noun classification system point out a number of correlations or covariations between the phonological form of nouns and their grammatical gender. In an extremely detailed study, Tucker, Lambert, and Rigault (1977) looked at correlations between grammatical gender and noun ending. They showed that a noun's ending could be used to correctly determine its gender in $84.5 \%$ of the 31,619 noun entries in the Petit Larousse Dictionary. Their statistical data described various formal markers, including a word's last phoneme (/tis-y/ or /is-y/) or last two phonemes (/ti-sy/ or $/ 1$-sy/). No matter what type of marker is considered, there are always exceptions, sometimes many. The number of exceptions defines the predictive value of an ending (PVE) in such a way that the greater the number of exceptions, the lower the predictive value of the ending. For example, the final phoneme /e/ occurs in masculine and feminine nouns in approximately equal proportions in French, so its predictive value is low. As a general rule, the tendency for a given phoneme to occur in nouns of a given gender varies. If we look solely at the last phoneme, regularities that encompass larger phonologicalunits may be masked. For example, the phoneme /õ/ is a poor predictor of the feminine gender ( $70 \%$; i.e., $30 \%$ exceptions). However, if among these, we distinguish the ending /jô/ from $/ \mathrm{b} \tilde{o} /, / \mathrm{ro} /$, and so forth, the predictive value changes: $91 \%$ of the nouns ending in $/ \mathrm{jo} /$ are feminine, and $87 \%$ of the nouns ending in /bõ/,/rô/, and so forth are masculine. Obviously, the more phonemes considered, the greater the predictive value. Most final phonemes are also part of more regular orthographic patterns. Accordingly, if we take the orthographic form of the sole final phoneme into account, the predictive value of an ending can change significantly. For example, the final phoneme/e/, which is an ambiguous predictor of gender, is part of a number of different orthographic sequences, including the sequence -ée, which marks the feminine (92\%), and the sequence $-e r$, which marks the masculine (100\%). These data suggest that noun endings are likely to provide some gender in- formation, and one can wonder whether native speakers can use this information in order to determine the gender of new words. The fact that a connectionistnetwork was able to "learn" the gender system for German nouns (MacWhinney, Leinbach, Taraban, \& McDonald, 1989; Zubin \& Köpcke, 1981) suggests that this is theoretically possible. Moreover, several studies have shown that native speakers of French take ending regularities into account by a very early age and use them to determine the grammatical gender of pseudonouns, as well as real nouns. KarmiloffSmith (1979) found that native French-speaking 3-yearolds already relied on phonological ending to attribute a gender to pseudowords. Similar results were obtained by Tucker et al. (1977), whose speakers, 7 to 18 years of age, categorized pseudowords in a way that directly reflected the distribution of endings in the two genders. The more regular the relationship between a given final phoneme and a given gender, the greater the number of subjects who attributed that gender to the pseudowords with that ending. For example, $67 \%$ of nouns ending in $/ \mathrm{k} /$ are masculine, and $65 \%$ of the subjects categorized pseudowords with that ending as masculine. Moreover, when the subjects were given the written form of a pseudoword, their responses were found to reflect the predictive value of the orthographic transcription of the final phoneme. For example, $99 \%$ of the words whose final phoneme $/ \mathrm{k} /$ is spelled - $c$ (as in floric) are masculine, and $90 \%$ of the subjects attributed masculine gender to such pseudowords. Similarly, the final phoneme $/ \mathrm{k} /$, spelled -que (as in florique), is ambiguous (55\% masculine, $45 \%$ feminine), and only $30 \%$ of the subjects said that such pseudowords were masculine. Studies on gender categorization of real words have also shown that noun endings can be used as formal gender cues. Desrochers, Paivio, and Desrochers (1989) and Desrochers and Paivio (1990), who presented the written form of isolated nouns to native French speakers and asked them to state the gender, showed that gender was determined faster and more accurately when the noun's ending was predictive of its gender than when it provided little gender information (Desrochers \& Paivio, 1990; Desrochers et al., 1989). Similar findings on the effect of ending-based gender predictability on the speed and accuracy of gender categorization were obtained by Bates, Devescovi, Pizzamiglio, D' Amico, and Hernandez (1995) with Italian stimuli presented aurally.

\section{Gender in Visual Word Recognition}

Going one step further, one can wonder whether this type of information can be used on line in reading situations in order to facilitate word recognition. For example, it could be argued that gender is identified at some point during the recognition process and that lexical search is subsequently restricted to those lexical units marked with that gender. The available empirical evidence concerning this question seems to favor a negative answer. For example, Desrochers et al. (1989; Desrochers \& Paivio, 1990) found an effect of the predictive value of endings for the gender categorization task, but not for the naming task, 
which suggests that gender can be taken into account only when subjects are explicitly required to determine noun gender. A similar finding was obtained by Bates et al. (1995). But it seems unwise to draw strong conclusions from these null results. So the first aim of the present study was to further examine the role of gender-related orthographic regularities as a function of task requirements in an experiment conducted with another widely used tasknamely, the lexical decision task (Andrews, 1989; Balota \& Chumbley, 1985; McRae, Jared, \& Seidenberg, 1990).

Note that we will be concerned here only with the visual modality. As far as the auditory modality is concerned, an early influence of gender-related regularities is much more problematic. Speech stimuli are delivered over time, and for many words recognition occurs before the ending has had a chance to be processed (Marslen-Wilson \& Welsh, 1978). In such circumstances, it can hardly be argued that final phonemes are used to predict the gender of the stimulus. This does not mean that gender cannot influence auditory word recognition (see Akhutina, Kurgansky, Polinsky, \& Bates, 1999; Bates, Devescovi, Hernandez, \& Pizzamiglio, 1996; Guillelmon \& Grosjean, 2001). For example, Grosjean, Dommergues, Cornu, Guillelmon, and Besson (1994) observed earlier recognition points in gating and faster reaction times in lexical decision for nouns preceded by an article marked for gender (e.g., "une joli(e) table," which means a pretty table) than for ones that were not gender marked. In this experiment, gender marking on the article apparently served as a powerful cue to recognition of the subsequent noun, probably by predicting the word ending. In other words, what Grosjean et al. showed is that gender-related regularities can be used in the gender-to-form direction (as opposed to the form-to-gender direction). This distinction will be further discussed in relation to the results of Experiment 2. By contrast, printed words are spatial objects, which means that all letters, including the last ones, are theoretically available for processing at the same time. Such an assumption is inherent in many models of word recognition-in particular, activation models (McClelland \& Rumelhart, 1981; Paap, Newsome, McDonald, \& Schvaneveldt, 1982), which take it for granted that all letter positions simultaneously activate a set of feature, letter, and, ultimately, word units. In this framework, predictive word endings are likely to help determine the stimulus gender before identification is completed (it can be assumed that, at some point during the activation process, most of the activated word units will share the same gender). On the other hand, the notion that all letters are processed in parallel can be questioned. It is a well-known fact that visual acuity rapidly drops off as soon as one moves away from the center of the fovea. As a consequence, the few letters around the fixation point are probably granted an advantage, as compared with letters located farther away (see Pynte, 1996, for a discussion). In other words, it is likely that the initial set of activated word units will be determined as a function of these central letters, rather than the final ones, with gender-related orthographic information becoming available only at a later stage of the recognition process. This notion will be further discussed in relation to Experiment 3.

\section{EXPERIMENT 1}

Experiment 1 used a lexical decision task. The PVE was manipulated. The PVE was based here on gender information conveyed by the orthographic form of the wordfinal phoneme, whose transcription is usually a bigram. High-predictive endings were bigrams predicting gender with fewer than $30 \%$ exceptions (e.g., [un] briqu-et [lighter]; -et appears in masculine nouns in $100 \%$ of the cases); low-predictive endings were bigrams predicting gender with more than $30 \%$ exceptions (e.g., [un] sty-le [style]; -le appears in masculine nouns in $52 \%$ of the cases). The choice of final bigram predictivity was supported by Tucker et al.'s (1977) observations showing that when visual stimuli are used, orthography-based gender information takes precedence over phonology-based gender information. If gender information is used strategically when the reader has to consciously identify the gender of a stimulus, as was stated by Desrochers et al. (1989) and Desrochers and Paivio (1990), no gender information effects should be observed on lexical decision performance. In contrast, the existence of such effects would indicate that grammatical gender is processed and used automatically during isolated noun recognition. A second aim of Experiment 1 was to further examine the role of the PVE for low- versus high-frequency words. The lack of a PVE $\times$ word frequency interaction in Desrochers et al.'s experiments was interpreted as an indication that PVE does not play any role in lexical access. The relevance of this argument can be questioned, however, since the tasks used by Desrochers et al. (gender categorization and naming) were possibly not well adapted for tracking early lexical access processes. It thus seems important to determine whether a different result can be found with a different task—namely, lexical decision. In summary, Experiment 1 manipulated three factors: PVE (low vs. high), word frequency (high vs. low), and gender (masculine vs. feminine).

\section{Method}

Subjects. Twenty-three students (ages, 20-35 years) at the University of Nice-Sophia Antipolis, France, participated in the experiment and were given course credit. All were native speakers of French and had normal or corrected-to-normal vision.

Materials. Eighty-eight inanimate nouns were selected, 44 masculine and 44 feminine (see Appendix A). In each set, half of the nouns had a high word frequency (mean frequency: 432 occurrences per million for masculine nouns and 461 for feminine nouns), and the other half had a low word frequency (mean frequency: 9.5 occurrences per million for masculine nouns and 9.8 for feminine nouns), as defined by the computerized French lexical database Brulex developed by Content, Mousty, and Radeau (1990). In each subset, half of the noun endings had a high PVE (mean PVE: .99 for masculine nouns and .95 for feminine nouns), and the other half had a low PVE (mean PVE: .52 for masculine nouns and .52 for feminine nouns), according to Tucker et al.'s (1977) tables. The eight experimental 
Table 1

Experiment 1: Mean Lexical Decision Time (in Milliseconds) and Error Rate (\%E) for the Eight Conditions Defined by Taking All Combinations of Gender, Word Frequency, and Predictive Value of Ending

\begin{tabular}{ccccccc}
\hline & \multicolumn{4}{c}{ Predictive Value of Ending } \\
\cline { 2 - 4 } \cline { 6 - 7 } Gender & Word Frequency & $M$ & $\% \mathrm{E}$ & & $M$ & $\% \mathrm{E}$ \\
\cline { 3 - 4 } Masculine & low & 715 & 8 & & 654 & 4 \\
& high & 578 & 2 & & 558 & 1 \\
Feminine & low & 678 & 7 & & 697 & 6 \\
& high & 551 & 1 & & 576 & 1 \\
\hline
\end{tabular}

conditions defined by taking all combinations of the gender (masculine vs. feminine), word frequency (high vs. low), and PVE (high vs. low) factors were represented by 11 nouns each. The eight sets of nouns were matched for length (mean length: 6.36 [low PVE and frequency], 6 [low PVE and high frequency], 6 [high PVE and frequency], and 6.27 [high PVE and low frequency] for masculine nouns; 5.9 [low PVE and frequency], 6 [low PVE and high frequency], 6 [high PVE and frequency], and 6 [high PVE and low frequency] for feminine nouns) and were controlled for final bigram frequency. Final bigram frequency was defined as the number of lexical units in which a given bigram occurred in the last position, out of the 30,000 lexical units considered (Content \& Radeau, 1988).

Procedure. At the start of each trial, a fixation point was displayed in the center of a computer screen. After $200 \mathrm{msec}$, it was replaced by a stimulus item, which remained on the screen until the subject's response. The subjects were instructed to determine as quickly and as accurately as possible whether the item was a word or a pseudoword. They responded by pressing the yes or no button (lexical decision task). The yes button was associated with the subject's dominant hand. After a series of 20 practice trials, the experimental materials were presented. The presentation order was randomized for each subject, who saw a total of 140 items ( 88 test items and 52 word-like pseudowords).

\section{Results}

The average lexical decision times on correct responses and the error rates are given in Table 1. Lexical decision times below $300 \mathrm{msec}$ and above $1,300 \mathrm{msec}$ were elimi- nated from the analyses. They represented $1 \%$ of the data. Analyses of variance were performed on correct responses, using subjects $\left(F_{1}\right)$ and items $\left(F_{2}\right)$ as random variables.

The analyses revealed that the only significant main effect was observed for word frequency $\left[F_{1}(1,22)=154\right.$, $\left.p<.0005 ; F_{2}(1,80)=119, p<.0005\right]$. Lexical decision times were significantly shorter for high-frequency nouns than for low-frequency ones. The main effects of gender and PVE were not significant $\left[F \mathrm{~s}<1\right.$, and $F_{1}(1,22)=$ $2.21, p>.10, F_{2}(1,80)=1.58, p>.10$, respectively]. The interaction between word frequency and PVE was significant $\left[F_{1}(1,22)=4.89, p<.05 ; F_{2}(1,80)=3.71, \mathrm{p}=.05\right.$; Figure 1]. Planned comparisons revealed a PVE effect that approached significance when word frequency was low [676 vs. $696 \mathrm{msec}$ for high- and low-PVE low-frequency words, respectively; $F_{1}(1,22)=4.87, p<.05 ; F_{2}(1,40)=$ 2.93, $p=.09$ ], whereas no PVE effect was obtained when word frequency was high $\left(F_{\mathrm{S}}<1\right)$.

The interaction between gender and PVE approached significance $\left[F_{1}(1,22)=20.04, p<.0005 ; F_{2}(1,80)=3.64\right.$, $p=.06$; Figure 2]. Planned comparisons revealed that for masculine nouns, lexical decision times were significantly shorter in the high-PVE condition than in the low one [606 vs. $646 \mathrm{msec} ; F_{1}(1,22)=21.01, p<.0005 ; F_{2}(1,40)=4.72$, $p<.05]$. Inversely, for feminine nouns, lexical decision times were longer with a high PVE than with a low PVE, but the difference was significant only in the subject analysis [636 vs. $\left.614 \mathrm{msec} ; F_{1}(1,22)=4.95, p<.05 ; F_{2}<1\right]$. Furthermore, response times were longer for masculine nouns than for feminine ones in the low-PVE condition, although this difference was significant in the subject analysis only [646 vs. $614 \mathrm{msec} ; F_{1}(1,22)=12.98, p<.0025$; $\left.F_{2}<1\right]$, whereas they were longer for feminine nouns than for masculine ones in the high-PVE condition, and the difference approached significance [606 vs. $636 \mathrm{msec}$; $\left.F_{1}(1,22)=11.68, p<.005 ; F_{2}(1,40)=3.42, p=.07\right]$.

The interaction between word frequency and gender was not significant $\left(F_{\mathrm{S}}<1\right)$, nor was the interaction be-

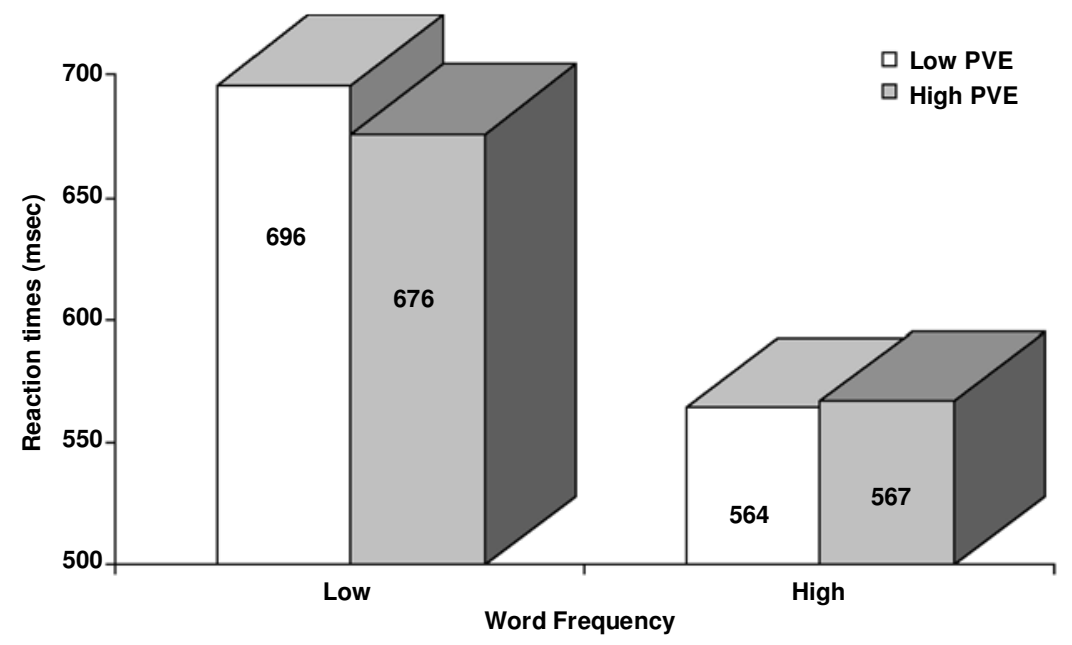

Figure 1. Experiment 1: Mean reaction time (in milliseconds) as a function of predictive value of ending (PVE) and word frequency. 


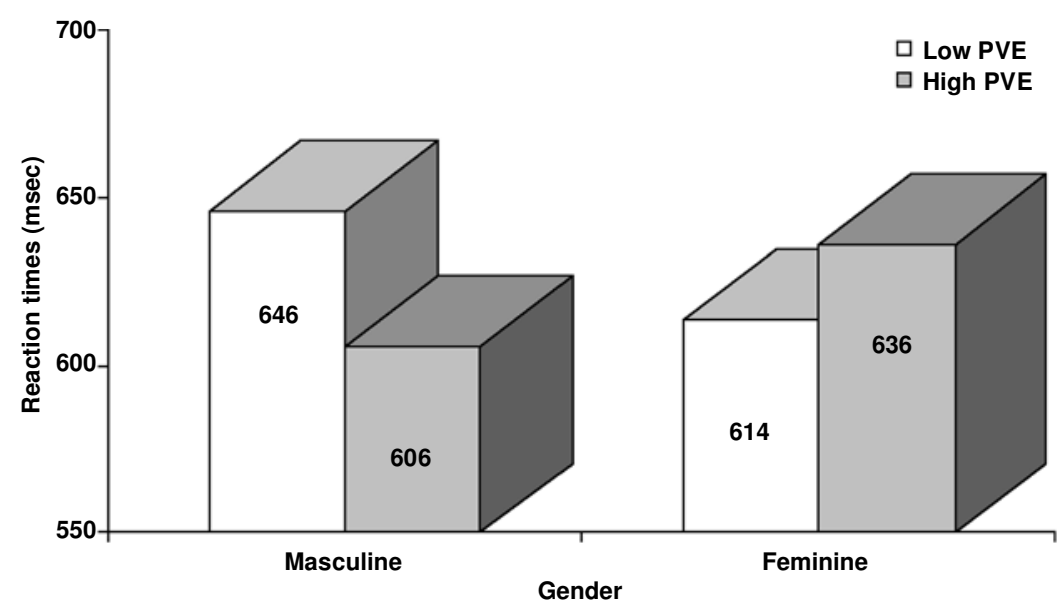

Figure 2. Experiment 1: Mean reaction time (in milliseconds) as a function of predictive value of ending (PVE) and gender.

tween the three manipulated factors $\left[F_{1}(1,22)=1.25, p>\right.$ $\left..10 ; F_{2}<1\right]$. The analysis of error rates revealed a significant main effect of word frequency $\left[F_{1}(1,22)=20.04\right.$, $\left.p<.0005 ; F_{2}(1,80)=17.20, p<.0005\right]$.

The error rate was lower for high-frequency nouns than for low-frequency ones. No other effect was significant [gender, $F_{\mathrm{S}}<1$; PVE, $F_{1}(1,22)=1.92, p>.10, F_{2}(1,80)=$ $2.13, p>.10$; word frequency $\times$ PVE, $F_{1}<1, F_{2}(1,80)=$ $1.80, p>.10$; gender $\times$ PVE, $F_{1}(1,22)=1.60, p>.10$, $F_{2}<1$; word frequency $\times$ gender, $F_{\mathrm{S}}<1$; word frequency $\times$ gender $\times$ PVE, $F \mathrm{~s}<1]$.

\section{Discussion}

The results of this first experiment are consistent with the notion that gender information can be used at some point during lexical access. As was expected, a significant interaction was found between PVE and word frequency, with a PVE effect approaching significance for lowfrequency nouns only. For these nouns, lexical decision times were shorter in the high PVE condition than in the low one (676 vs. $696 \mathrm{msec}$ ). This result contradicts those obtained by Desrochers et al. (1989) with a gender categorization task, as well as those of Bates et al. (1995) obtained with a repetition task. Following Desrochers et al.'s (1989; Desrochers \& Brabant, 1995; Desrochers \& Paivio, 1990) line of reasoning, one can thus conclude that the predictive value of word endings exerts its influence during the word recognition process. In order to explain the lack of the PVE effect in the high-frequency condition, it could be argued that recognition was too fast in this case for the PVE to be taken into account. Colé, Magnan, and Grainger (1999) used a similar argument to account for the finding that phonologicalfactors did not seem to affect recognition time in the case of high-frequency words, as opposed to low-frequency words.

The results also revealed an interaction between gender and PVE. Lexical decision times were shorter for masculine items with a high PVE than for masculine items with a low PVE, whereas PVE exerted little influence for feminine items. This pattern of results can probably be better understood if one assumes that the cue to gender used by the subjects was not the whole ending (e.g., the final bigram corresponding to the orthographic transcription of the last phoneme), as was expected, but rather the last letter in the word. As was mentioned above, the feminine nouns we used all ended in $e$, a letter that supplies little information about gender on its own. Among nouns ending in $e$ in French, $42 \%$ are masculine and 58\% are feminine, so $e$ has a low predictive value. On the other hand, endings predictive of the masculine gender generally end in a letter other than $e$. The fact that a word ends in a letter other than $e$ is thus predictive of the masculine gender (among nouns without a final $e, 80 \%$ are masculine). In summary, for most masculine nouns and for the masculine nouns we used, the ending (last bigram) and the last letter have similar predictive values (either low or high). Inversely, for most feminine nouns and for the feminine nouns we used, regardless of their PVE, the last letter is always nonpredictive. In order to investigate the role of the final letter (either $e$ or a letter different from $e$ ) as a possible cue to gender, we conducted an experiment in which all items, including masculine ones, ended in $e$. If the unit readers use as a gender cue is the last letter, rather than a phonemic/orthographic unit corresponding to the final bigram, PVE effects on masculine nouns should disappear.

\section{EXPERIMENT 2}

In this experiment, all masculine and feminine nouns ended in $e$. This letter in final position has a low predictive value because it occurs equally often in feminine and masculine nouns (in 58\% and $42 \%$ of the cases, respectively). Thus, if a noun's last letter is the intralexical cue to gender used by French readers, one could assume that no PVE effects would be observed in this second experiment. On the other hand, if such effects were still ob- 
tained, this would suggest that larger units are used as a cue to gender.

\section{Method}

Subjects. Twenty-eight students (ages, 20-35 years) at the University of Nice-Sophia Antipolis, France, participated in the experiment. All were native speakers of French and had normal or correctedto-normal vision.

Materials. Thirty-two inanimate nouns were selected (16 masculine and 16 feminine), all ending in the nonpredictive letter $e$ (see Appendix B). In each set, the nouns were divided into two equal subsets: one with high predictive value of the final bigram (mean PVE: .93 for masculine nouns and .93 for feminine nouns) and one with low predictive value of the final bigram (mean PVE: .51 for masculine nouns and .50 for feminine nouns) according to Tucker et al.'s (1977) tables. The two factors, gender (masculine vs. feminine) and PVE (low vs. high), determined four categories, each represented by 8 nouns. The four sets of items were matched for length (mean length: 6.8 characters for masculine-low-PVE, 6 for masculinehigh-PVE, 6.5 for feminine-low-PVE, and 6.6 for feminine-highPVE) and for word frequency (mean word frequency: 9.8 occurrences per million for masculine-low-PVE, 10 for masculine-highPVE, 10 for feminine-low-PVE, and 10.6 for feminine-high-PVE). Bigram frequency was again controlled using Content and Radeau's (1988) tables (mean bigram frequency: 2,469 for masculine-lowPVE, 2,379 for masculine-high-PVE, 2,494 for feminine-low-PVE, and 3,288 for feminine-high-PVE).

Procedure. The procedure was the same as that in the preceding experiment (lexical decision task). A series of 20 practice items were presented before the experimental materials. The stimulus presentation order was randomized for each subject, who saw a total of 104 items. There were 32 test items and 72 fillers: 40 pseudonouns, and 32 nouns ending with a letter other than $e$ to avoid strategies based on list content.

\section{Results}

Average lexical decision times on correct responses, and error rates are given in Table 2. Lexical decision times below $300 \mathrm{msec}$ and above $1,300 \mathrm{msec}$ were eliminated from the analyses. They represented $1.4 \%$ of the data. Analyses of variance were performed using subjects $\left(F_{1}\right)$ and items $\left(F_{2}\right)$ as random variables.

The main effect of PVE was not significant $\left[F_{1}(1,27)=\right.$ $\left.1.05, p>.10 ; F_{2}<1\right]$, whereas the main effect of gender was significant in the subject analysis $\left[F_{1}(1,27)=23.37\right.$, $\left.p<.005 ; F_{2}(1,28)=1.48, p>.10\right]$. Lexical decisions were shorter for feminine nouns than for masculine ones. The interaction between gender and PVE was not significant $\left(F_{\mathrm{S}}<1\right)$. An analysis of the error rates yielded a main effect of PVE that approached significance $\left[F_{1}(1,27)=\right.$ $\left.28.79, p<.00025 ; F_{2}(1,28)=3.25, p=.08\right]$ and a main effect of gender, significant in the subject analysis $\left[F_{1}(1,27)=17.67, p<.001 ; F_{2}(1,28)=1.58, p>.10\right]$. The subjects made more errors on nouns with a high PVE than on nouns with a low PVE and on masculine nouns than on feminine ones. The interaction between these two factors was also significant in the subject analysis $\left[F_{1}(1,27)=18.18, p<.005 ; F_{2}(1,28)=2.1, p>.10\right]$. Planned comparisons revealed that the PVE effect approached significance for masculine nouns $\left[F_{1}(1,27)=\right.$ $\left.39.70, p<.0001 ; F_{2}(1,14)=4.24, p=.06\right]$, but not for feminine ones $\left[F_{1}(1,27)=1.00, p>.10 ; F_{2}<1\right]$.
Table 2

Experiment 2: Mean Lexical Decision Time (in Milliseconds) and Error Rate (\% E) for the Four Conditions Defined by Taking All Combinations of Gender and Predictive Value of Ending (Last Letter $=e$ )

\begin{tabular}{|c|c|c|c|c|}
\hline \multirow[b]{3}{*}{ Gender } & \multicolumn{4}{|c|}{ Predictive Value of Ending } \\
\hline & \multicolumn{2}{|c|}{ Low } & \multicolumn{2}{|c|}{ High } \\
\hline & $M$ & $\% \mathrm{E}$ & $M$ & $\% \mathrm{E}$ \\
\hline Masculine & 635 & 4 & 624 & 17 \\
\hline Feminine & 599 & 4 & 590 & 6 \\
\hline
\end{tabular}

\section{Discussion}

The results showed that when the last letter was not predictive of the noun's gender, the predictive value of the noun's final bigram no longer influenced response times. Moreover, the error data yielded a reverse PVE effect for masculine nouns, with more errors when the noun ending (last bigram) was predictive of gender than when it was not. This finding may be the consequence of some kind of interference between the last letter and the last bigram in gender prediction. It is important to note, from this point of view, that the probability that a masculine noun will end with a final $e$ is low. Even though the final $e$ is not predictive of the feminine gender (as was indicated above, it is present in masculine and feminine nouns in nearly equal proportions), it is, in fact, typical of feminine nouns (73\% of the feminine nouns actually end in the letter $e$, whereas $67 \%$ of the masculine nouns end in a letter other than $e$ ). In other words, the presence versus the absence of the letter $e$ at the end of a given noun is relatively predictable, once the gender of this noun has been determined. This somehow paradoxical peculiarity of French orthography might have caused the interference effects mentioned above and could also explain why feminine items were apparently easier to identify than masculine ones. The latter effect can be interpreted in terms of last-letter predictability. Remember that all items, including masculine ones, ended in the letter $e$ in Experiment 2, which means that last-letter predictability was high for feminine items and low for masculine ones, whatever the PVE.

In summary, the results of Experiment 2 suggest that two types of orthographic regularities associated with gender are likely to influence lexical decision times, the first one operating in the ending-to-genderdirection (predicting gender from ending), and the second one in the gender-to-ending direction (predicting the last letter from gender). The aim of Experiment 3 was to further investigate the role of these two types of regularities in word recognition. Whereas ending-to-gender predictability (e.g., PVE) could, in principle, operate at a relatively early stage of lexical access (e.g., by reducing the set of lexical candidates to those belonging to the gender category predicted by the stimulus ending; see Bates et al., 1996, Schriefers, Friederici, \& Rose, 1998, Tanenhaus, Dell, \& Carlson, 1987, and more recently, Dahan, Swingley, Tanenhaus, \& Magnuson, 2000, for discussions of this notion), gender-to-last letter predictability cannot enter into play 
before gender has been determined, which probably means once the word has been fully identified. In this view, the locus of the effects found in Experiment 2 is probably to be looked for in some kind of postaccess verification stage, without any relevance vis-à-vis normal word recognition.

Although this might be true as far as isolated words are concerned, last-letter predictability is likely to play a role in connected reading, whenever the gender of a word can be predicted by the preceding context. French nouns are usually preceded by a gender-marked determiner (e.g., the articles $l e$ or $l a$ for masculine and feminine items, respectively), which means that gender is usually available in advance (e.g., before the eye has reached the noun), so that the last letter can in fact be predicted before recognition is completed. A third experiment was thus conducted, with the aim of analyzing how the two types of gender-related orthographic regularitiesidentified in Experiment 2 (namely, PVE and last-letter predictability) influence lexical access processes when gender information is provided in advance by a gender-marked determiner.

\section{EXPERIMENT 3}

In Experiment 3, each item was preceded by the definite article le or la, depending on its gender. Again, high- and low-PVE feminine and masculine words were presented. As in Experiment 1, all feminine items, as well as lowPVE masculine items, ended in a final $e$. Only high-PVE masculine items ended in a letter different from $e$. In order to get a more precise idea concerning the locus of gender effects in this type of situation, an eye-tracking procedure was used. Eye movement analysis, unlike the more traditional measures of word recognition, allows for the possibility of mapping the time course of processing by way of a succession of fixations (Pynte, Kennedy, \& Murray, 1991). If orthographic regularities are used during lexical access, gender-related effects can be expected to occur on early measures of visual inspection (e.g., first-fixation durations). By contrast, if orthographic regularities are exploited during a postaccess verification stage, gender effects should show up on later measures (e.g., refixation probability; see Pynte, 1996, for a discussion).

\section{Method}

Subjects. Twenty students (ages, 20-30 years) at the University of Provence participated in the experiment. All were native speakers of French and had normal, uncorrected vision.

Materials. Twenty masculine and 20 feminine inanimate nouns were selected (see Appendix C). In each set, half of the noun endings were highly predictive of the noun's gender (mean PVE: .99 for masculine nouns and .90 for feminine nouns), and the other half had a low predictive value, according to Tucker et al.'s (1977) tables (mean PVE: .52 for masculine nouns and .50 for feminine nouns). As in the first experiment, nouns in the masculine-low-predictive condition and nouns in both feminine conditions ended in $e$, whereas nouns in the masculine-high-predictive condition ended with a letter other than $e$. The four experimental conditions defined by taking all combinations of the gender (masculine vs. feminine) and PVE (low vs. high) factors were represented by 10 nouns each. The four sets of nouns were matched for length (mean length: 6.6 for lowPVE masculine nouns, 6.4 for high-PVE masculine nouns, 6.3 for low-PVE feminine nouns, and 6.6 for high-PVE feminine nouns), word frequency (mean frequency: 101 occurrences per million for low-PVE masculine nouns, 100 for high-PVE masculine nouns, 100 for low-PVE feminine nouns, and 103 for high-PVE feminine nouns), and final bigram frequency, on the basis of Content and Radeau (1988) (mean frequency: 1,805 for low-PVE masculine nouns, 2,024 for high-PVE masculine nouns, 1,984 for low-PVE feminine nouns, and 2,129 for high-PVE feminine nouns). The stimulus presentation order was randomized for each subject, who saw a total of 90 items, 40 test items and 50 fillers (pseudonouns). Each item was presented with the article le or $l a$ (masculine and feminine forms of the) that agreed in gender with the item when it was a noun.

Procedure and Apparatus. During the experiment, the subject's head was held in place with adjustable head- and chinrests. Eye movements were monitored by a standard spectacle-mounted infrared limbus tracking device. Output from the horizontal detectors of the right eye was sampled every $5 \mathrm{msec}$ by an OPUS 386 PC computer. The eye-tracking system was aligned and calibrated for each subject. The subjects were asked to look, in turn, at five points, the third of which was located in the center of the area to be occupied by the stimuli. A calibration phase was repeated every four trials. Stimuli (article + letter sequence) appeared centered on a computer screen, and the subjects had to indicate whether or not the letter sequence was a word by pressing one of two response buttons (lexical decision task). Each stimulus was preceded by a fixation point. When the subject first pressed the button, the fixation point was replaced by an item. The fixation point was located where the blank between the article and the target word would appear. Ten practice stimuli were presented before the experimental materials.

\section{Results}

As was mentioned above, the stimuli were presented in such a way that the blank between the article and the target noun coincided with the location of a preceding fixation point. The first fixation on the stimulus was thus expected to occur on the blank. This was not always the case, however. The first fixation sometimes occurred slightly to the left or right of the expected position. To eliminate any bias, all deviations above one character were eliminated from the analyses. These cases represented $7.8 \%$ of all the trials. Typically, the pattern of inspection recorded on a stimulus included a relatively quick saccade (mean latency: $195 \mathrm{msec}$ ) that took the eye to a position located approximately at the middle of the noun (position 2.7 from the noun beginning, on average). Seven percent of the trials did not involve such an initial rightward saccade and were excluded from the analyses. At that point, different cases can be distinguished, according to whether the eye moves or not (multifixation vs. single-fixation strategy), exits the noun or not (inspection of the article vs. noun refixation), or goes leftward or rightward (regressive vs. progressive refixation of the noun). The influence of gender and PVE at each of these decision points was analyzed in terms of probability and saccade latency. The results are summarized in Table 3.

Probabilities. The single-fixation strategy represented $37 \%$ of the cases, on average. This proportion did not vary significantly as a function of any of the experimental factors (all $F_{\mathrm{S}}<1$ ). When a second saccade was observed on the stimulus (which occurred in $63 \%$ of the remaining 
cases), the probability that the following fixation would be located on the article rather than on the noun was .40 , on average. This probability varied as a function of the noun properties - namely, gender and PVE. The interaction between gender and PVE was marginally significant $\left[F_{1}(1,19)=6.51, p=.02 ; F_{2}(1,36)=3.00, p=.09\right]$. Planned comparisons indicated that the probability of observing a saccade toward the article was not affected by PVE for masculine nouns $\left[F_{1}(1,19)=1.17, p>.10\right.$; $\left.F_{2}(1,18)=1.36, p>.10\right]$. For feminine nouns, this probability was higher for the low-PVE condition than for the high-PVE condition. But this difference was significant for the subject analysis only $\left[F_{1}(1,19)=5.90, p=.02\right.$; $\left.F_{2}(1,18)=1.65, p>.10\right]$. The main effects of gender and PVE were not significant $(F \mathrm{~s}<1)$. When the second saccade recorded on the stimulus was directed toward the noun, the probability that the following fixation would be at the noun ending rather than at the noun beginning was .55 , on average. This probability varied as a function of the properties of the noun ending (high vs. low PVE), with more rightward refixations for the high-PVE condition than for the low-PVE condition. This was true for both feminine and masculine nouns. The main effect of PVE was significant $\left[F_{1}(1,19)=5.97, p=.02 ; F_{2}(1,36)=\right.$ $13.30, p=.001]$. The interaction between PVE and gender was nonsignificant $\left(F_{\mathrm{S}}<1\right)$, as was the main effect of gender $\left(F_{\mathrm{S}}<1\right)$.

Saccade latencies. When the second saccade was directed toward the article, saccade latencies were not significantly affected by any of the factors manipulated in the experiment (all $F_{2} \mathrm{~s}<1.50$ ). The situation was different for noun refixations. Rightward-saccade latencies (refixation of the noun ending) were shorter for masculine nouns than for feminine nouns $\left[F_{1}(1,19)=11.44, p<\right.$ $.003 ; F_{2}(1,36)=3.72, p=.06$, for the main effect of gender]. No other significant effect was revealed by the analysis of variance (all $F \mathrm{~s}<1$ or close to 1 ). As far as leftward saccades are concerned (refixations of the noun beginning), the analysis of variance revealed a marginally significant interaction between gender and PVE $\left[F_{1}(1,19)=\right.$ $\left.6.08, p=.02 ; F_{2}(1,36)=2.48, p>.10\right]$. Saccade latency was not affected by PVE for feminine nouns $\left(F_{\mathrm{S}}<1\right)$ but was significantly shorter in the low-PVE condition than in the high-PVE condition for masculine nouns $\left[F_{1}(1,19)=\right.$ $\left.29.80, p=.0001 ; F_{2}(1,36)=4.45, p=.05\right]$. The main effects of gender and PVE were not significant $\left(F_{1}\right.$ and $F_{2}$ close to 1 for the main effect of gender; $F_{2}<2$ for the main effect of PVE).

Duration of the subsequent fixation. Table 3 also indicates the duration of the subsequent fixation (third column), which corresponds to the total time spent on the noun (single-fixation strategy), to the duration of the fixation made on the article (article inspection strategy), or to the duration of the second fixation made on the noun (beginning- and ending-refixation strategies). None of these measures was affected by the noun properties (all $F_{2} \mathrm{~s}<1$ or close to 1 ).

\section{Discussion}

The PVE was thus found to influence within-word inspection strategies: The probability of inspecting the word ending was higher for high-PVE items than for low-PVE ones. The effect was present for both feminine and masculine items (no significant gender $\times$ PVE interaction), although the difference was greater in the masculine condition (.72 vs. .55 for high-PVE and low-PVE masculine items, respectively, as compared with .58 vs. .53 for feminine items). Interestingly, rightward-saccade latencies were shorter for masculine items, as a whole, as compared with feminine ones, which suggests that the triggering mechanisms were possibly different (remember that both high- and low-PVE feminine items ended in the letter $e$, whereas the final letter was different for high- and lowPVE masculine items). Conversely, more leftward withinword saccades (i.e., saccades directed toward the noun beginning) were observed in the low-PVE condition than in the high-PVE condition, and again, the difference was greater for masculine items than for feminine ones. However, a significant gender $\times$ PVE interaction was found for saccade latencies in this case. When the refixation saccade was directed toward the word beginning, its latency was longer for high-PVE masculine items than for lowPVE masculine items (no difference between the two feminine conditions), which suggests that leftward withinword saccades were in the "wrong direction" for highPVE masculine items.

Table 3

Experiment 3. Saccade Latency (Lat.; in Milliseconds), Probability of Inspection Strategies (Pb.), and Subsequent Fixation Duration (Dur.; in Milliseconds) as a Function of Gender and Predictive Value of Ending

\begin{tabular}{|c|c|c|c|c|c|c|c|c|c|c|c|}
\hline \multirow{4}{*}{$\begin{array}{c}\text { Predictive } \\
\text { Value of Ending } \\
\end{array}$} & \multirow{3}{*}{\multicolumn{2}{|c|}{$\begin{array}{c}\text { Single-Fixation } \\
\text { (vs. Multifixation) } \\
\text { Strategy } \\
\end{array}$}} & \multicolumn{9}{|c|}{ Multifixation Strategies } \\
\hline & & & \multirow{2}{*}{\multicolumn{3}{|c|}{$\begin{array}{c}\text { Article Refixation } \\
\text { (vs. Noun Refixation) }\end{array}$}} & \multicolumn{6}{|c|}{ Noun Refixation } \\
\hline & & & & & & \multicolumn{3}{|c|}{ Beginning Refixation } & \multicolumn{3}{|c|}{ Ending Refixation } \\
\hline & $\mathrm{Pb}$. & Dur. & Lat. & $\mathrm{Pb}$. & Dur. & Lat. & $\mathrm{Pb}$. & Dur. & Lat. & $\mathrm{Pb}$. & Dur. \\
\hline \multicolumn{12}{|c|}{ Masculine } \\
\hline Low & .36 & 423 & 344 & .48 & 155 & 239 & .45 & 226 & 266 & .55 & 243 \\
\hline High & .37 & 377 & 366 & .54 & 166 & 296 & .28 & 190 & 249 & .72 & 226 \\
\hline \multicolumn{12}{|c|}{ Feminine } \\
\hline Low & .40 & 421 & 311 & .53 & 174 & 255 & .47 & 229 & 306 & .53 & 230 \\
\hline High & .36 & 408 & 324 & .40 & 158 & 267 & .42 & 220 & 292 & .58 & 228 \\
\hline
\end{tabular}


The predictive value of word endings also exerted an influence on the probability of inspecting the article. As far as feminine items are concerned, this probability was lower in the high-PVE condition-that is, when the gender of the article was consistent with the gender predicted from the word ending. No such difference showed up for masculine items, however, which, again, can probably be attributable to the fact that the last letter was different from $e$ for the high-PVE masculine condition. The processing of high-PVE masculine items apparently involved the inspection of both the word ending and the article, whereas fewer article-directed saccades were recorded for high-PVE feminine items. This difference between feminine and masculine items, in the high-PVE condition, can be interpreted in terms of last-letter predictability. More precisely, it can be argued that gender-to-orthography checking mechanisms were easier to achieve in the feminine condition. Predicting the presence of a specific letter (namely, $e$ ) in the feminine case was probably easier than predicting the absence of the letter $e$ (any letter but $e$ ) in the masculine case.

\section{GENERAL DISCUSSION}

The main issue addressed in the experiments reported in this paper concerned the processing of gender during visual word recognition. This question was examined by looking at how regularities in the noun classification system of French affect lexical decision speed and accuracy and eye inspection strategies. The results, as a whole, revealed an effect of noun classification regularities during the processing of nouns with an arbitrary gender, even though the task requested of the subjects (lexical decision) did not require them to process this kind of information. For example, Experiment 1 revealed an interaction between the PVE and lexical frequency. For low-frequency items, lexical decision times were shorter when the word ending was a good predictor of its gender than when it was not (no significant difference in the case of high-frequency items). The gender information conveyed by a noun ending thus seems to have an impact on lexical access, at least as far as low-frequency words are concerned. This first result seems inconsistent with the hypothesis put forward by Desrochers et al. (1989; Desrochers \& Paivio, 1990) and Bates et al. (1995) that gender information is processed only when the requested task focuses specifically on this kind of processing.

Experiment 1 also revealed an interaction between gender and PVE, with shorter lexical decision times for highPVE masculine items than for the other three types of items. This pattern of results was interpreted as an indication that the last letter, rather than the whole ending (e.g., the last bigram), was possibly used as the cue to gender in Experiment 1, since the only condition in which the last letter was different from $e$ was apparently granted an advantage. The importance of the last letter was confirmed by Experiment 2, in which all the items, either masculine or feminine and either high- or low-PVE, ended in the letter $e$. The predictive value of word endings no longer had any effect when the identity of the last letter was maintained constant in this way. A main effect of gender was found instead, with shorter lexical decision times for feminine items than for masculine ones. The latter finding led us to suspect that the letter $e$ could play a special role when located at the end of a feminine noun. Gender-related orthographic regularities can, in fact, be considered from two distinct points of view. A noun's ending can be used to predict its gender with more or less certainty (orthographyto-gender direction), and conversely, its gender can be used to predict its last letter (gender-to-orthography direction). This distinction is important because it can provide an insight into the time course of lexical access processes. Orthography-to-genderregularities are likely to operate at a moment at which gender is not yet determined (i.e., probably before identification is completed), whereas gender-to-orthography regularities can operate only once gender has been determined - that is, either after the word has been fully identified or during some late stage of the recognition process. By examining which of these two types of regularities underlies gender effects, it should thus be possible to shed some light regarding the moment at which gender is taken into account during word recognition. For example, in the framework of the activationverification model (Paap et al., 1982), word recognition is viewed as the result of two successive stages-namely, an initial activation stage, during which a set of lexical candidates is activated on the basis of perceptual and contextual information, and a subsequent selection stage, during which the candidate that best matches the stimulus is eventually selected. Gender could theoretically enter into play at both of these stages. For example, it could be argued that the set of initial lexical candidates is restricted to a single gender, either feminine or masculine, as a function of orthographic and contextual information (e.g., gender information conveyed by the word ending and the preceding context, if any; see Bates et al., 1996, and Schriefers et al., 1998, for similar interpretations) and that the stimulus ending is subsequently checked for last-letter compatibility during the selection stage.

The locus of gender effects was further examined in an eye-tracking experiment. As in the two preceding experiments, high- and low-PVE feminine and masculine nouns were presented. Gender-to-last-letter predictability was maintained constant for feminine items (all feminine items ended in the highly predictive letter $e$ ) but was different for masculine items. Whereas low-PVE masculine items ended in the letter $e$ (low last-letter predictability), high-PVE masculine items ended in a letter different from $e$ (high last-letter predictability). Contextual gender information was provided by the presence of the definite article la (feminine) for feminine items or le (masculine) for masculine items. The first fixation was forced onto the blank between the article and the noun. The results indicated that this first fixation was relatively short and was immediately followed by a saccade that took the eye to a convenient viewing position within the noun. This enter- 
ing saccade was typically followed by a second one, taking the eye to the noun ending, the noun beginning, or the article. The latency and location of this second saccade were affected by the stimulus properties manipulated in the experiment.

Most important, a main effect of PVE was found for the probability of making a refixation toward the word ending. When the noun-final bigram was predictive of gender, the probability that the eyes would move toward that ending, rather than toward the word beginning, was greater than when the final bigram was nonpredictive. The fact that a main PVE effect, rather than a gender $\times$ PVE interaction, was found suggests that the gender-related orthographic regularities manipulated in the experiment exerted their influence in the orthography-to-genderdirection, rather than in the gender-to-orthography direction. The effect apparently was due to the possibility of predicting gender from word ending, a mechanism likely to operate at a moment when gender is not yet determined. If the determining factor was the predictability of the last letter, an interaction between gender and PVE would have been observed, since the last letter of feminine nouns was always predictable, whereas the last letter of masculine nouns was predictable only in the high-PVE condition. From this result, it could thus be tempting to conclude that the locus of the effect has to be looked for in an early stage of lexical access (e.g., the activation stage of the activationverification model).

This conclusion must be considered with caution, however. First, it should be noted that the effect in question was found for a relatively late measure of visual inspectionnamely, the probability of making a refixation toward the noun ending. There is, in fact, no direct evidence in the data that gender exerted any influence during the early stages of lexical access. Second, the above conclusion was based on the absence of a PVE $\times$ gender interaction, and it must be admitted that the data were not clear-cut from this point of view. Although no significant interaction was found, the PVE effect was, in fact, stronger for masculine than for feminine items. Moreover, a significant gender $X$ PVE interaction was found for leftward saccades, directed either toward the noun beginning (longer latencies for high-PVE than for low-PVE masculine items, no difference for feminine items) or toward the article (lower probability for high-PVE than for low-PVE feminine items, no difference for masculine items). The finding that PVE played differently for feminine and masculine items, as far as leftward saccades are concerned, suggests that some kind of checking mechanism, probably triggered by the presence of the article, was involved in this case.

A similar checking mechanism possibly was responsible for the main effect of the PVE found for rightward refixations. For example, it could be argued that gender was initially determined on the basis of the article and that refixations were subsequently triggered in order to check the word ending for compatibility. Note that such an interpretation would not necessarily mean that gender information is of no use for lexical access. First of all, it should be noted that the presence of determiners is mandatory in French. This means that native speakers of French are continuously confronted with many co-occurrences of a given noun and a given article, and it would not be surprising that stored associations between nouns and articles contribute to gender processing during reading. Desrochers et al. (1989; Desrochers \& Brabant, 1995; Desrochers \& Paivio, 1990) went even further, since they suggested that gender information is actually represented in the mental lexicon in the form of an association between nouns and determiners. In this view, checking the article and/or the word ending for gender compatibility can be considered as a normal processing step whenever an article + noun sequence is presented. In favor of their hypothesis, Desrochers et al. pointed out that native speakers of French usually have more trouble determining the gender of certain nouns that begin with a vowel and, thus, require a neutral determiner (e.g., l' or mon [the and my], used before both masculine and feminine nouns) than for nouns that start with a consonant (Arrivé, Gadet, \& Galmiche, 1985; Desrochers \& Brabant, 1995; Desrochers \& Paivio, 1990; Desrochers et al., 1989). Moreover, when asked to state gender by answering un or une (masculine and feminine forms of the indefinite article $a$ ), native French speakers always respond faster than when asked to choose between masculine and feminine (Desrochers \& Brabant, 1995; Desrochers \& Paivio, 1990; Desrochers et al., 1989).

In conclusion, although the noun classification system of French is described as arbitrary, it exhibits a number of regularities between noun endings and gender. The results obtained here suggest that French speakers are capable of detecting these regularities and putting them to work in recognizing nouns. Our results suggest that at least in the written language, French readers have acquired a body of multiply interconnected gender information encoded in the lexicon that involves different levels of language organization, including the sublexical level (which is the predictive value of the ending), the lexical level (the gender category), and the morphosyntactic level (the relationship between articles and nouns).

\section{REFERENCES}

Akhutina, T., Kurgansky, A., Kurganskaya, M., Polinsky, M., Plonskaya, N., Larina, O., Bates, E., \& Appelbaum, M. (2001). Processing of grammatical gender in normal and aphasic speakers of Russian. Cortex, 37, 295-326.

Akhutina, T., Kurgansky, A., Polinsky, M., \& Bates, E. (1999). Processing of grammatical gender in a three-gender system: Experimental evidence from Russian. Journal of Psycholinguistic Research, 28, 695-713.

ANDREWS, S. (1989). Frequency and neighborhood size effects on lexical access: Activation or search? Journal of Experimental Psychology: Learning, Memory, \& Cognition, 15, 802-814.

Arnold, J. E., Eisenband, J. G., Brown-Schmidt, S., \& Trueswell, J. C. (2000). The rapid use of gender information: Evidence of the time course of pronoun resolution from eyetracking. Cognition, 76, B 13-B26.

Arrivé, M., Gadet, F., \& Galmiche, M. (1985). La grammaire d'aujourd'hui. In Guide alphabétique de la langue française. Paris: Flammarion.

Balota, D. A., \& Chumbley, J. I. (1985). The locus of word-frequency 
effects in the pronunciation task: Lexical access and/or production? Journal of Memory \& Language, 24, 89-106.

Bates, E., Devescovi, A., Hernandez, A., \& Pizzamiglio, L. (1996). Gender priming in Italian. Perception \& Psychophysics, 85, 9921004.

Bates, E., Devescovi, A., Pizzamiglio, L., D’Amico, S., \& HernanDEZ, A. (1995). Gender and lexical access in Italian. Perception \& Psychophysics, 57, 847-862.

Bates, E., Marangolo, P., Pizzamiglio, L., \& Dick, F. (2001). Linguistic and nonlinguistic priming in aphasia. Brain \& Language, 76, 62-69.

Blumstein, S. E., Milberg, W. P., Dworetzky, B., Rosen, A., \& GerSHBERG, F. (1991). Syntactic priming effects in aphasia: An investigation of local syntactic dependencies. Brain \& Language, 40, 393-421.

Cacciari, C., Carreiras M, \& Coonini, C. B. (1997). When words have two genders: Anaphor resolution for Italian functionally ambiguous words. Journal of Memory \& Language, 37, 517-532.

Carreiras, M., Garnham, A., \& OAKhill, J. (1993). The use of superficial and meaning-based representations in interpreting pronouns: Evidence from Spanish. European Journal of Cognitive Psychology, 5, 93-116.

Colé, P., Magnan, A., \& Grainger, J. (1999). Syllable-sized units in visual word recognition: Evidence from skilled and beginning readers of French. Applied Psycholinguistics, 20, 507-532.

ColÉ, P., \& SEgui, J. (1994). Grammatical incongruency and vocabulary types. Memory \& Cognition, 22, 387-394.

Content, A., Mousty, P., \& Radeau, M. (1990). Brulex: Une base de données lexicales informatisée pour le français écrit et parlé. L'Année Psychologique, 90, 551-566.

Content, A., \& Radeau, M. (1988). Données statistiques sur la structure orthographique du français. Cahiers de Psychologie Cognitiv (Numéro Hors-série).

Corbett, G. G. (1991). Gender (Cambridge Textbooks in Linguistics). Cambridge: Cambridge University Press.

Dahan, D., Swingley, D., Tanenhaus, M. K., \& Magnuson, J. S. (2000). Linguistic gender and spoken-word recognition in French. Journal of Memory \& Language, 42, 465-480.

Desrochers, A. (1986). Genre grammatical et classification nominale. Canadian Journal of Psychology, 40, 224-250.

Desrochers, A., \& Brabant, M. (1995). Lexical categorization. Revue Canadienne de Psychologie Expérimentale, 49, 240-262.

Desrochers, A., \& Paivio, A. (1990). Le phonème initial des noms inanimés et son effet sur l'identification du genre grammatical. Revue Canadienne de Psychologie, 44, 44-57.

Desrochers, A., Paivio, A., \& Desrochers, S. (1989). L'effet de la fréquence d'usage des noms inanimés et de la valeur prédictive de leur terminaison sur l'identification du genre. Revue Canadienne de Psychologie, 43, 62-73.

Deutsch, A., Bentin, S., \& Katz, L. (1999). Semantic influence on processing gender agreement: Evidence from Hebrew. Journal of Psycholinguistic Research, 28, 515-535.

Friederici, A. D., \& JACOBSEN, T. (1999). Processing grammatical gender during language comprehension. Journal of Psycholinguistic Research, 28, 467-483.

Garnham, A., Oakhill, J., Ehrlich, M.-F., \& Carreiras, M. (1995). Representations and processes in the interpretation of pronouns: New evidence from Spanish and French. Journal of Memory \& Language, 34, 41-62.

Grosjean, F., Dommergues, J. Y., Cornu, E., Guillelmon, D., \& BEsson, C. (1994). The gender-marking effect in spoken word recognition. Perception \& Psychophysics, 56, 590-598.

Guillelmon, D., \& Grosjean, F. (2001). The gender marking effect in spoken word recognition: The case of bilinguals. Memory \& Cognition, 29, 503-511.

Gurjanov, M., Lukatela, G., Lukatela, K., Savic, M., \&
Turvey, M. T. (1985). Grammatical priming of inflected nouns by the gender of possessive adjectives. Journal of Experimental Psychology: Learning, Memory, \& Cognition, 11, 692-701.

Jakubowicz, C., \& Goldblum, M. C. (1995). Processing of number and gender inflections by French-speaking aphasics. Brain \& Language, 51, 242-268.

JAREMA, G., \& Friederici, A. D. (1994). Processing articles and pronouns in agrammatic aphasia: Evidence from French. Brain \& Language, 46, 683-694.

KARMiloff-Smith, A. (1979). A functional approach to child language: A study of determiners and reference. Cambridge: Cambridge University Press.

Lyons, J. (1968). Introduction to theoretical linguistics. Cambridge: Cambridge University Press.

MacWhinney, B., Leinbach, J., Taraban, R., \& McDonald, J. (1989). Language learning: Cues or rules? Journal of Memory \& Language, 28, 255-277.

Marslen-Wilson, W. D., \& Welsh, A. (1978). Processing interactions and lexical access during word recognition in continuous speech. Cognitive Psychology, 10, 29-63.

McClelland, J. L., \& Rumelhart, D. E. (1981). An interactive activation model of context effects in letter perception: Pt. 1. An account of basic findings. Psychological Review, 88, 375-407.

McDonald, J. L., \& MacWhinney, B. (1995). The time-course of anaphor resolution: Effects of implicit verb causality and gender. Journal of Memory \& Language, 34, 543-566.

McRae, K., JARED, D., \& SeIDEnberg, M. S. (1990). On the roles of frequency and lexical access in word naming. Journal of Memory \& Language, 29, 43-65.

Mel'Cuk, I. (1993). Cours de morphologie générale (théorique et descriptive) : Vol. 1. Introduction et première partie: Le mot. Montreal: Les Presses de l'Université de Montréal.

Paap, K. R., Newsome, S. L., McDonald, J. E., \& Schvaneveldt, R. W. (1982). An activation-verification model of letter and word recognition: The word superiority effect. Psychological Review, 89, 573-594.

Pynte, J. (1996). Lexical control of within-word eye movements. Journal of Experimental Psychology: Human Perception \& Performance, 22, 958-969.

Pynte, J., Kennedy, A., \& Murray, W. S. (1991). Within-word inspection strategies in continuous reading: Time-course of perceptual, lexical, and contextual processes. Journal of Experimental Psychology: Human Perception \& Performance, 17, 458-470.

Schriefers, H., Friederici, A. D., \& Rose, U. (1998). Context effects in visual word recognition: Lexical relatedness and syntactic context. Memory \& Cognition, 26, 1292-1303.

SÉGUIN, H. (1969). Les marques du genre dans le lexique français écrit contemporain: Compilation des cas et essai de classement. Mémoire de D.E.S. Montréal: Université de Montréal, Département de Linguistique.

Tanenhaus, M. K., Dell, S. G., \& Carlson, G. (1987). Context effects and lexical processing: A connectionist approach to modularity. In J. L. Garfield (Ed.), Modularityin knowledgerepresentation andnaturallanguage processing (pp. 83-108). Cambridge, MA: MIT Press.

Tucker, G. R., Lambert, W. E., \& Rigault, A. A. (1977). The French speaker's skill with grammatical gender: An example of rule-governed behavior. The Hague: Mouton.

VIgliocco, G., \& ZILLI, T. (1999). Syntactic accuracy in sentence production: The case of gender disagreement in Italian language impaired and unimpaired speakers. Journal of Psycholinguistic Research, 28, 623-648.

Zubin, D., \& KöPCKE, K. (1981). Gender: A less arbitrary grammatical category. In R. Hendrick, C. Masek, \& M. Miller (Eds.), Papers from the Seventeenth Regional Meeting (pp. 439-449). Chicago: Chicago Linguistic Society. 
APPENDIX A

Experiment 1: Materials

\begin{tabular}{|c|c|c|c|c|c|c|c|}
\hline $\begin{array}{c}\text { Low-Frequency } \\
\text { Nouns }\end{array}$ & $\begin{array}{c}\text { Word } \\
\text { Frequency }\end{array}$ & PVE & $\begin{array}{c}\text { Bigram } \\
\text { Frequency }\end{array}$ & $\begin{array}{c}\text { High-Frequency } \\
\text { Nouns }\end{array}$ & $\begin{array}{c}\text { Word } \\
\text { Frequency }\end{array}$ & PVE & $\begin{array}{c}\text { Bigram } \\
\text { Frequency } \\
\end{array}$ \\
\hline \multicolumn{8}{|c|}{ Masculine } \\
\hline Microbe & 16.47 & 60 & 227 & principe & 420.99 & 45 & 227 \\
\hline Glaive & 14.79 & 31 & 416 & fleuve & 151.18 & 31 & 31 \\
\hline Cloporte & 2.83 & 63 & 4,682 & miracle & 162.99 & 52 & 4,682 \\
\hline Dialecte & 3.40 & 63 & 4,682 & exemple & 676.47 & 52 & 4,442 \\
\hline Socle & 11.92 & 52 & 4,442 & texte & 213.40 & 63 & 4,682 \\
\hline Saule & 19.89 & 52 & 4,442 & geste & 647.91 & 63 & 4,682 \\
\hline Dédale & 8.64 & 52 & 4,442 & sable & 171.18 & 52 & 4,442 \\
\hline Puzzle & 2.83 & 52 & 4,442 & style & 186.20 & 52 & 4,442 \\
\hline Périple & 3.18 & 52 & 4,442 & siècle & 538.26 & 52 & 4,442 \\
\hline Concile & 7.27 & 52 & 4,442 & article & 245.24 & 52 & 4,442 \\
\hline Grade & 17.83 & 31 & 1,591 & monde & $2,735.05$ & 31 & 1,591 \\
\hline Cadran & 13.07 & 99 & 371 & roman & 303.13 & 99 & 371 \\
\hline Bambou & 7.62 & 97 & 251 & genou & 246.71 & 97 & 251 \\
\hline Calepin & 4.76 & 99 & 1,312 & portrait & 171.52 & 100 & 447 \\
\hline Clavecin & 6.47 & 99 & 1,312 & chemin & 565.91 & 99 & 1,312 \\
\hline Civet & 2.83 & 100 & 917 & jardin & 400.40 & 99 & 1,312 \\
\hline Béret & 13.53 & 100 & 917 & objet & 862.35 & 100 & 917 \\
\hline Galet & 15.11 & 100 & 917 & billet & 114.30 & 100 & 917 \\
\hline Cornet & 12.94 & 100 & 917 & regret & 147.51 & 100 & 917 \\
\hline Beignet & 4.20 & 100 & 917 & projet & 295.75 & 100 & 917 \\
\hline Gobelet & 9.44 & 100 & 917 & paquet & 116.23 & 100 & 917 \\
\hline Briquet & 11.82 & 100 & 917 & cabinet & 124.54 & 100 & 917 \\
\hline \multicolumn{8}{|c|}{ Feminine } \\
\hline Harpe & 13.63 & 55 & 429 & troupe & 301.76 & 55 & 429 \\
\hline Ogive & 7.38 & 69 & 416 & preuve & 220.21 & 69 & 416 \\
\hline Secte & 16.71 & 37 & 4,682 & carte & 200.64 & 37 & 4,682 \\
\hline Comète & 8.98 & 37 & 4,682 & route & 642.01 & 37 & 4,682 \\
\hline Fiole & 11.36 & 48 & 4,442 & école & 277.99 & 48 & 4,442 \\
\hline Pilule & 5.11 & 48 & 4,442 & table & 679.20 & 48 & 4,442 \\
\hline Cabale & 5.32 & 48 & 4,442 & étoile & 246.26 & 48 & 4,442 \\
\hline Sandale & 10 & 48 & 4,442 & parole & 777.59 & 48 & 4,442 \\
\hline Boussole & 6.36 & 48 & 4,442 & méthode & 218.40 & 69 & 1,591 \\
\hline Horde & 10.45 & 69 & 1,591 & période & 182.78 & 69 & 1,591 \\
\hline Tornade & 7.16 & 69 & 1,591 & attitude & 315.78 & 69 & 1,591 \\
\hline Orgie & 13.29 & 98 & 2,862 & pluie & 240.35 & 98 & 2,862 \\
\hline Toupie & 6.71 & 98 & 2,862 & série & 133.88 & 98 & 2,862 \\
\hline Hostie & 14.33 & 98 & 2,862 & théorie & 170.96 & 98 & 2,862 \\
\hline Poulie & 8.53 & 98 & 2,862 & énergie & 204.06 & 98 & 2,862 \\
\hline Momie & 8.53 & 98 & 2,862 & industrie & 115.67 & 98 & 2,862 \\
\hline Dièse & 5.56 & 92 & 2,892 & crise & 200.70 & 92 & 2,892 \\
\hline Clause & 12.49 & 92 & 2,892 & chaise & 218.40 & 92 & 2,982 \\
\hline Écluse & 13.74 & 92 & 2,892 & phrase & 468.07 & 92 & 2,982 \\
\hline Punaise & 8.64 & 92 & 2,892 & chose & $3,715.24$ & 92 & 2,982 \\
\hline Ardoise & 15 & 92 & 2,892 & église & 466.60 & 92 & 2,982 \\
\hline Ventouse & 4.87 & 92 & 2,892 & analyse & 180.40 & 92 & 2,982 \\
\hline
\end{tabular}

Note-PVE, predictive value of ending. 
APPENDIX B

Experiment 2: Materials

\begin{tabular}{lccclcrc}
\hline $\begin{array}{l}\text { Masculine } \\
\text { Nouns }\end{array}$ & $\begin{array}{c}\text { Word } \\
\text { Frequency }\end{array}$ & PVE & $\begin{array}{c}\text { Bigram } \\
\text { Frequency }\end{array}$ & $\begin{array}{c}\text { Feminine } \\
\text { Nouns }\end{array}$ & $\begin{array}{c}\text { Word } \\
\text { Frequency }\end{array}$ & $\begin{array}{c}\text { PVE } \\
\text { Bigram } \\
\text { Frequency }\end{array}$ \\
Gnome & 1.90 & 92 & 2,178 & biscotte & 1.50 & 96 & 4,682 \\
Adage & 2.30 & 94 & 2,580 & cassette & 2.40 & 96 & 4,682 \\
Bocage & 2.50 & 94 & 2,580 & douille & 2.60 & 83 & 4,442 \\
Marasme & 3.30 & 92 & 2,178 & nacelle & 3.80 & 90 & 4,442 \\
Arôme & 10.70 & 92 & 2,178 & calorie & 5.00 & 98 & 2,862 \\
Potage & 8.98 & 94 & 1,580 & denrée & 11.90 & 92 & 1,168 \\
Diplôme & 14.33 & 92 & 2,178 & fusée & 26.40 & 92 & 1,168 \\
Fromage & 36.00 & 94 & 2,580 & écurie & 31.60 & 98 & 2,862 \\
Girofle & 1.50 & 52 & 4,442 & escalope & 1.80 & 55 & 429 \\
Poulpe & 1.60 & 45 & 429 & valve & 1.90 & 69 & 416 \\
Horoscope & 2.80 & 45 & 429 & belote & 2.60 & 37 & 4,682 \\
Dialecte & 3.40 & 63 & 4,682 & timbale & 4.40 & 48 & 4,442 \\
Trèfle & 7.20 & 52 & 4,442 & tulipe & 8.70 & 55 & 429 \\
Glaive & 14.80 & 31 & 416 & soucoupe & 8.30 & 55 & 429 \\
Microbe & 16.50 & 60 & 227 & secte & 16.70 & 37 & 4,682 \\
Pacte & 31.15 & 63 & 4,682 & épingle & 37.30 & 48 & 4,442 \\
\hline
\end{tabular}

Note-PVE, predictive value of ending.

APPENDIX C

Experiment 3: Materials

\begin{tabular}{lccclrrr}
\hline $\begin{array}{l}\text { Masculine } \\
\text { Nouns }\end{array}$ & $\begin{array}{c}\text { Word } \\
\text { Frequency }\end{array}$ & PVE & $\begin{array}{c}\text { Bigram } \\
\text { Frequency }\end{array}$ & $\begin{array}{c}\text { Feminine } \\
\text { Nouns }\end{array}$ & $\begin{array}{c}\text { Word } \\
\text { Frequency }\end{array}$ & $\begin{array}{c}\text { PVE } \\
\text { Frequency }\end{array}$ \\
\hline Globe & 41.39 & 60 & 227 & rubrique & 7.38 & 45 & 3,628 \\
Microbe & 16.47 & 60 & 227 & fresque & 15.70 & 45 & 3,628 \\
Proverbe & 18.42 & 60 & 227 & lessive & 17.72 & 69 & 429 \\
Groupe & 373.88 & 45 & 429 & digue & 26.60 & 42 & 3,628 \\
Fleuve & 151.18 & 31 & 416 & cravate & 51.28 & 37 & 4,682 \\
Tumulte & 47.19 & 63 & 4,682 & tempe & 51.18 & 55 & 429 \\
Peigne & 16.26 & 39 & 3,651 & grève & 61.18 & 69 & 416 \\
Masque & 95.53 & 55 & 3,628 & formule & 171.18 & 48 & 4,442 \\
Colloque & 7.16 & 55 & 3,628 & preuve & 220.21 & 69 & 416 \\
Miracle & 162.99 & 52 & 4,442 & faute & 394.95 & 37 & 4,682 \\
Boniment & 10.21 & 99 & 3,249 & faïence & 13.64 & 85 & 2,440 \\
Soutien & 16.92 & 99 & 1,955 & calomnie & 16.26 & 98 & 2,862 \\
Tilleul & 25.35 & 99 & 145 & cheville & 23.42 & 90 & 4,442 \\
Gilet & 30.48 & 100 & 917 & fusée & 26.39 & 92 & 1,168 \\
Coussin & 35.43 & 99 & 1,312 & marée & 43.77 & 92 & 1,168 \\
Ruban & 55.27 & 99 & 371 & bougie & 47.75 & 98 & 2,862 \\
Climat & 66.66 & 99 & 147 & galerie & 62.61 & 98 & 2,862 \\
Talent & 103.61 & 99 & 3,249 & paille & 90.64 & 90 & 4,442 \\
Quartier & 224.10 & 100 & 6,602 & bataille & 242.51 & 90 & 4,442 \\
Train & 448.50 & 99 & 1,312 & classe & 246.15 & 85 & 2,892 \\
\hline Note- PVE & & & & &
\end{tabular}

Note-PVE, predictive value of ending.

(Manuscript received March 6, 1998;

revision accepted for publication August 26, 2002.) 